\title{
Microwave pyrolysis of pecan nutshell and thermogravimetric, textural and spectroscopic characterization of carbonaceous products
}

\author{
G. Durán-Jiménez ${ }^{\text {ac }}$, V. Hernández-Montoya a, ${ }^{\text {a, }}$, M.A. Montes-Morán ${ }^{\mathrm{b}}$, S. W. Kingman ${ }^{\mathrm{c}}$, T. \\ Monti ${ }^{\mathrm{c}}$, E. R. Binner ${ }^{\mathrm{c}}$,
}

${ }^{a}$ TecNM/Instituto Tecnológico de Aguascalientes, Av. Adolfo López Mateos No. 1801 Ote. C.P. 20256, Aguascalientes, México.

${ }^{b}$ Instituto Nacional del Carbón, INCAR-CSIC, Apartado 73 E-33080, Oviedo, Spain. ${ }^{c}$ Microwave Process Engineering Research Group, Faculty of Engineering, University Park, University of Nottingham, Nottingham, NG7 2RD, UK

\begin{abstract}
In the present work, the pyrolysis of pecan nut shell was studied using microwave technology at different input power and exposure time. The carbonaceous products were characterized using elemental analysis, potentiometric titration, thermogravimetric analysis, $\mathrm{N}_{2}$ adsorption isotherms at $-196{ }^{\circ} \mathrm{C}$ and FT-IR spectroscopy. The characteristics of microwave carbonaceous products were compared with carbons prepared by conventional heating and commercial carbons and finally, the interaction of textile dyes with the carbonaceous materials was studied. The results are indicating that it is possible to obtain carbonaceous materials with similar textural parameters in conventional and microwave systems, but for microwave heating the processing times are short $(3 \mathrm{~min})$. Also, the exposure time of $2 \mathrm{~min}$ of microwave are not enough for the complete depolymerization of the lignocellulosic matrix of the nut shell and significant amount of cellulose and hemicelluloses remain in char after microwave treatment. Finally, all the carbons obtained by microwave heating are
\end{abstract}

${ }^{*}$ Corresponding author. Tel.: +52 4499105002 Ext. 137

E-mail address: virginia.hernandez@yahoo.com.mx (Virginia Hernández-Montoya) 
microporous materials with a high number of basic groups on their surface and the high molecular size of dyes is controlling the adsorption on these materials. Key words: Carbons, Microwave Technology, Pyrolysis, Textile dyes

\section{Introduction}

Carbonaceous adsorbents are widely used for the removal of pollutants from wastewater due to their characteristics such as chemical functionalities and textural parameters. In recent years, several biomasses as vegetable sponge of cylindrical loofa, bamboo, pistachio shell, date sphate, flamboyant, olive-waste cake, crop straws, prickly pear peels, white sapote seeds, carnauba palm and others have been used for the preparation of carbonaceous adsorbents [19]. The method commonly used to prepare activated carbons (AC's) with high surface area through physical and/or chemical activation is conventional heating in a tubular furnace. The fundamental process of conventional heating is heat transfer to the precursor by conduction, convection and radiation mechanisms. The main problem of conventional heating is that, in some cases, the thermal process may take several hours and the process incurs extra processing costs. Additionally, the thermal gradient from the hot surface of the sample to its interior impedes the effective removal of gaseous products to the surroundings; consequently, the carbon quality decreases [10]. Microwave heating has emerged as an alternative method to prepare activated carbons (AC's). During microwave heating, electromagnetic energy is converted directly to heat by dipole rotation and ionic conduction of active molecules. Microwaves heat volumetrically, which means they supply energy as heat instantaneously throughout the sample; the degree of heating within a component varies depending on its composition, and this gives rise to the ability of microwaves to selectively heat different 
system components. The volumetric and selective heating mechanisms provide advantages such as rapid temperature rise throughout the bulk of the sample, uniform temperature distribution and targeted heating, resulting in reduced treatment times (and hence process energy savings) and improved product quality compared with conventional thermal methods [11-15]. The continued development of activated carbon technologies with new applications of microwave heating in preparing activated carbons using waste biomass as precursor is succeeding and expanding and specifically, the microwave preparation of adsorbents for the removal of dyes is one area that has received attention. For example, Deng et al. have reported the preparation of activated carbons to remove $\mathrm{BB} 9$ using cotton stalk and $\mathrm{H}_{3} \mathrm{PO}_{4}$ as the activating agent [16]. Also, Pezoti et al. described the use of nut endocarp by the preparation of activated carbon using $\mathrm{ZnCl}_{2}$ as the activating agent for the adsorption of $\mathrm{BB} 9$ [17]. Likewise, researchers have successfully demonstrated the use of other activating agents such as $\mathrm{KMnO}_{4}$ [18], $\mathrm{KOH}$ [19], $\mathrm{FeCl}_{3}$ [20] and $\mathrm{K}_{2} \mathrm{CO}_{3}$ [21] to obtain activated carbons with high surface area from different biomasses by means of microwave heating. While these studies report the preparation of carbons with high specific surface for dyes removal, it is important to note that the preparation of these materials involved more than one step or the utilization of additional chemical (as activating agents), increasing the total production cost of AC's. In this regard, two common methods have been adopted in AC preparation using microwave heating: 1) Feedstock Impregnation (FI) process, in which the carbon precursor is preimpregnated with a microwave receptor $\left(\mathrm{SiC}\right.$, carbon, $\mathrm{H}_{3} \mathrm{PO}_{4}$ ) before being subject to microwave heating. In the FI process, the microwaves are absorbed by the receptors, which heat up and then transfer heat to the surrounding biomass particles via conventional heat transfer mechanisms to reach the carbonization level required. 2) Intermediate Char Impregnation (ICI) is the most widely used process for AC preparation by microwave heating 
to obtain material with high specific surface. This process includes two steps: in the first one, the carbon precursor is carbonized by conventional heating in inert atmosphere; the second one involves the impregnation of the charcoal obtained from the first step with an activating agent $\left(\mathrm{ZnCl}_{2}, \mathrm{~K}_{2} \mathrm{CO}_{3}\right.$, ) and microwave heating to produce $\mathrm{AC}$. The main disadvantage in the utilization of some of the two procedures described before is the extra costs associated with the use of more than one production step and the reagents used for the activation of carbon adsorbents. For this reason, the purpose of the present work is to evaluate the viability of using microwave irradiation to prepare carbon adsorbents using a waste biomass (nut shell) without the use of additional chemical microwave absorber or pre-carbonization by conventional heating. The significant influences of microwave power and radiation time on the surface chemical functionalities and porosity are experimentally tested. Additionally, the adsorption/desorption behavior of the resulting carbonaceous materials for three of the most used textile dyes in dying process i.e. Acid Orange 7 (AO7), Basic Blue 9 (BB9) and Reactive Black 5 (RB5) is investigated and the interaction of carbon surface-dyes was elucidated by molecular tools.

\section{Experimental}

\subsection{Materials and Methods}

\subsubsection{Pyrolysis of pecan nut shells and obtaining of carbonaceous materials}

Pecan nut shells were used as the precursor in the preparation of carbonaceous materials and they were obtained from an agrifood company in Aguascalientes, México. The shells were milled and sieved to obtain a particle size of $0.7 \mathrm{~mm}$. The obtained particles were washed and dried at $70{ }^{\circ} \mathrm{C}$ for $24 \mathrm{~h}$, with the purpose of avoiding decomposition. A fixed amount of nut shells (30 g) was placed in a single-mode microwave system and different combinations 
of microwave powers and radiation times. Nitrogen, at a flow rate of $5 \mathrm{~L} \mathrm{~min}^{-1}$, was used as a sweep gas to aid the removal of volatiles and to maintain an oxygen-free atmosphere within the system. The reflected microwave power was minimized by the manual 3 -stub tuner and the sliding short positioning, in order to maximize the power absorbed by the sample. Based on our previous results [22] the combination of $400 \mathrm{~W}$ and $500 \mathrm{~W}$ and radiation times of 2, 3, 4 and 5 min were selected to prepare the carbonaceous materials. The microwave system operated at frequency of $2450 \pm 25 \mathrm{MHz}$ has the characteristics described in a previous work [22], the principal components are shown in Fig. 1.

The energy absorbed by the sample was determined by numerical integration of absorbed power, $\left(\mathrm{P}_{\mathrm{A}}\right)$, according to the follow equation:

$$
E=\frac{\int P_{a} d t}{M}
$$

Where $E$ is the specific absorbed energy $(\mathrm{kJ} / \mathrm{kg}), t$ is the microwave exposure duration ( $\mathrm{sec})$, and $M$ is the initial mass of the sample $(\mathrm{g})$. Specifically, the absorbed power was calculated subtracting the reflected power $\left(\mathrm{P}_{\mathrm{R}}\right)$ from the input power $\left(\mathrm{P}_{\mathrm{I}}\right)$, from the signals obtained from the Agilent U2001a power sensors (See Fig. 1).

Sample labelling is as follows: $\mathrm{x}-\mathrm{y}$, where " $\mathrm{x}$ " is the microwave power and " $\mathrm{y}$ " is the exposure time used. After heating, the resulting materials were thoroughly washed with deionized water until the $\mathrm{pH}$ of the washing solution was constant. Finally, samples were sieved and dried at $110{ }^{\circ} \mathrm{C}$ for $24 \mathrm{~h}$.

\subsubsection{Preparation of carbonaceous materials using a conventional furnace}

For comparative studies, a carbon sample was prepared using conventional heating. The thermal treatment was carried out in a quartz reactor placed in a tubular furnace (Carbolite 
model CTF 12165/550). $30 \mathrm{~g}$ of precursor (nutshell) was carbonized in nitrogen atmosphere using a flow of $5 \mathrm{~cm}^{3} / \mathrm{min}$. The temperature program comprised of one heating ramp from room temperature until $650{ }^{\circ} \mathrm{C}$ at $3{ }^{\circ} \mathrm{C} / \mathrm{min}$ and dwelling time of 1 hour. Specifically, this maximum temperature of thermal treatment was selected according with DTG curves of pecan nut shell in $\mathrm{N}_{2}$ atmosphere (see Fig. $\mathrm{S} 2 \mathrm{a}$ ), where is possible to observe that the thermal degradation is completed at $650{ }^{\circ} \mathrm{C}[23]$.

The obtained carbon adsorbent was washed, sieved and dried using the same methodology described before. This material was denominated as Carbon Tubular Furnace (CTF).

\subsubsection{Commercial activated carbon source}

To compare the performance of carbon adsorbents obtained with microwave and conventional heating, a commercial activated carbon was used in this work. A bituminous based granular activated carbon, Filtrasorb 400 (F400) made by Calgon Carbon Corporation was sieved, washed and stored for later use.

\subsubsection{Characterization of carbonaceous adsorbents}

The characterization of the carbonaceous adsorbents prepared in this work was performed using analytical and physico-chemical methods. The content of carbon, hydrogen, nitrogen and sulfur was obtained with a LECO CHNS-932 elemental analyzer and the oxygen percentage was estimated by difference. Mid-infrared spectra of the solid carbons were acquired using a FTIR spectrometer (Thermo Nicolet-IS10 Thermoscientific) equipped with an ATR accessory. The point of zero charge was estimated following a previously reported methodology [24]. In this case, $0.150 \mathrm{~g}$ of each carbon was put in contact with $50 \mathrm{~mL}$ of 0.01 $\mathrm{M} \mathrm{NaCl}$ at different initial $\mathrm{pH}$ values for $24 \mathrm{~h}$. Initial $\mathrm{pH}$ values were adjusted by adding the 
appropriate amount of $\mathrm{NaOH}$ or $\mathrm{HCl}$ standards $(0.1 \mathrm{M})$ and the final $\mathrm{pH}$ was measured after $24 \mathrm{~h}$ under agitation at room temperature. The point of zero charge was determined as the $\mathrm{pH}$ value in a graph where the $\mathrm{pH}_{\text {final }}=\mathrm{pH}_{\text {initial. }}$ Thermogravimetric $(\mathrm{TG})$ and differential thermal gravimetric (DTG) analyses were performed with 20 mg of sample, using a TGA Q5000 from TA Instruments under air atmosphere and using a heating rate of $10{ }^{\circ} \mathrm{C} / \mathrm{min}$ from room temperature until $900{ }^{\circ} \mathrm{C}$. The moisture contents were calculated from the loss of weight at $105^{\circ} \mathrm{C}$. Likewise, the ash content was estimated by difference of the total loss of weight sample.

Finally, the textural properties of materials were obtained from nitrogen adsorption isotherms at $-196{ }^{\circ} \mathrm{C}$ using an automatic Micromeritics ASAP 2020 analyzer. Prior to taking the measurements, the samples were outgassed overnight at $300{ }^{\circ} \mathrm{C}$ under vacuum for $8 \mathrm{~h}$. The experimental data of isotherms were adjusted at different models in order to calculate the principal textural parameters. The surface area was calculated using the Brunauer-EmmettTeller (BET) model using the relative pressure $\left(\mathrm{P} / \mathrm{P}_{0}\right)$ range from 0.05 to 0.3 . The total pore volume was determined from the amount of nitrogen adsorbed at a relative pressure of $\sim 0.99$; the micropore volume was obtained by applying the Dubinin-Raduskevich method and, finally, the pore size distribution was obtained with the Barrett-Joyner-Halenda (BJH) desorption method.

\subsubsection{Dye adsorption-desorption test}

Acid Orange 7 (AO7), Reactive Black 5 (RB5) and Basic Blue 9 (BB9) are synthetic dyes used extensively in textile industries. Their properties were obtained using the Quantitative Structure Activity Relationships (QSAR) methodology implemented in the HyperChem ${ }^{\odot} 8.0$ 
software. The optimization of molecular geometries (lowest energy confirmation) was performed using the AMBER molecular force field. The structures and general characteristics of the dyes under study are depicted in Table 1.

To evaluate the interaction of dyes with the carbonaceous materials, adsorption experiments were carried out at $30{ }^{\circ} \mathrm{C}$. Specifically, $0.02 \mathrm{~g}$ of carbon was put in contact with $10 \mathrm{ml}$ of dye solution in plastic tube with a stock solution of $500 \mathrm{mg} / \mathrm{L}$ at $\mathrm{pH} 3$ or $\mathrm{pH}$ 7. The equilibrium time was determined by previous studies and was set to $72 \mathrm{~h}$ for all the dyes. After this equilibrium time was reached, the aqueous solution was decanted and the equilibrium concentration was determined by UV-Vis spectroscopy (Hach DR-5000 spectrophotometer) by using a calibration curve at the wavelength of maximum absorbance of each dye (see Table 1). The absorbance of each dye was measured using a quartz cell and the following equation was used to calculate the dye adsorption capacity of a given carbon:

$$
q=\frac{\left(C_{0}-C_{e}\right)}{m} V
$$

where $C_{0}$ and $C_{e}$ are the initial and equilibrium dye concentrations $(\mathrm{mg} / \mathrm{L})$, respectively, $V$ is the volume of the solution (L), and $m$ is the weight of the adsorbent $(\mathrm{g})$.

In order to investigate the desorption of dyes, the carbons loaded with each dye after the adsorption tests were placed in a plastic tube with $10 \mathrm{~mL}$ of deionized water at $\mathrm{pH} 3$ or 7 (the same $\mathrm{pH}$ of adsorption test). The suspension was mixed at $150 \mathrm{rpm}$ for $72 \mathrm{~h}$ in an incubator at $30{ }^{\circ} \mathrm{C}$. After $72 \mathrm{~h}$, the sorbent was separated from the aqueous solution and the dye concentration in the solution was determined as in the adsorption test. 
Triplicates of all adsorption-desorption tests were carried out and standard deviations of the results presented in this work were within $5 \%$ of average values.

\section{Results and discussion}

\subsection{Characterization of carbonaceous materials}

The elemental composition of the carbons prepared by microwave heating in the present work is shown in Table 2. A clear trend was observed in the carbon and oxygen contents of the two series of samples (obtained at 400 and $500 \mathrm{~W}$ ). Specifically, the percentage of carbon was higher in the samples obtained at longer exposure times; for the samples obtained at 400 $\mathrm{W}$, the increase was from 69 to $85 \%$, and for the samples prepared at $500 \mathrm{~W}$ from 76 to 85 $\%$, using exposure times of 2 and $5 \mathrm{~min}$, respectively. The opposite behavior was observed for the oxygen contents, i.e., the oxygen percentage was higher for the samples prepared at low exposure times $(2 \mathrm{~min})$. This higher oxygen content is related to the presence of oxygenated functional groups, as evidenced by the FT-IR spectra of the samples 400-2 and 500-2 (see Fig. 2) and the results are congruent with the carbons prepared from camellia oleifera shell by conventional-microwave carbonization [25].

For the two series of samples, is clear that the peaks corresponding to modes of vibration of functional groups are disappearing with increasing exposure time due to decomposition of functional groups. Particularly, in the samples obtained at 2 min the peak corresponding to stretching vibration $\mathrm{O}-\mathrm{H}$ of hydroxyl groups at $\sim 3350 \mathrm{~cm}^{-1}$ can be observed. In addition, the two peaks observed in the range between 2960 and $2800 \mathrm{~cm}^{-1}$ are assigned to asymmetric C$\mathrm{H}$ and symmetric $\mathrm{C}-\mathrm{H}$ stretching vibration of alkyl groups as methyl and methylene [26]. The 
peak localized between 1500 and $1650 \mathrm{~cm}^{-1}$ is related to the $\mathrm{C}=\mathrm{C}$ stretching vibration of aromatic structures and the peak at $\sim 1030 \mathrm{~cm}^{-1}$ is assigned to $\mathrm{C}-\mathrm{O}$ stretching vibration of unsaturated ethers [27]. Additionally, it is important to note that, according to the information reported in the literature these two latter assignations can be related to the possible formation of basic groups such as the pyrones [28].

In this context, the point of zero charge $\left(\mathrm{pH}_{\mathrm{pzc}}\right)$ of most carbons is high with values higher than 9, indicating that in general, the materials are rich in basic groups such as pyrone, chromene, carbonyl and ether (See Table 3 and Fig. S1 in supporting information). The only exception was the carbon obtained at $400 \mathrm{~W}$ for 2 min (400-2), where the $\mathrm{pH}_{\mathrm{pzc}}$ was slightly acidic (6.4), probably due to incomplete carbonization and consequently, the presence of acidic functional groups of cellulose, hemicellulose and lignin from the starting composition of nut shell. According with previous studies the pecan nut shells are constituted by cellulose (30\%), hemicellulose (26\%), lignin (41\%) and soluble compounds (3\%) [29] and the principal thermal effects observed at 333 and $496{ }^{\circ} \mathrm{C}$ are related to decomposition of these components (See Fig. S2 supporting information).

The thermogravimetric profiles of carbonaceous samples are presented in Fig. 3. The TG curves were separated according the microwave exposure time, the conventionally pyrolyzed carbon (CTF) and the commercial activated carbon (F400). The overall losses in the pyrolyzed materials obtained from nut shell (microwave and conventional pyrolysis) are in the range of $91.5 \%$ and $96 \%$, the remaining corresponding to the amount ashes of inorganic compounds present in the nut shell (calcium compounts). The commercial activated carbon F400 has $91.3 \%$ of losses with ash content of $8.7 \%$. The unique mass loss showed in F400 is due to decomposition of carbon at temperature of $630{ }^{\circ} \mathrm{C}$. The samples obtained in 
microwave and conventional heating have some similarities and mainly three regions of weight loss can be observed. In all samples at lower temperatures organic materials begin to undergo some thermal decomposition losing chemical bound moisture. For microwave carbon samples (Fig. 3a, 3b, 3c, 3d) this first region is in a range from $22-95{ }^{\circ} \mathrm{C}$ with mass losses of 1.2 to $4.4 \%$, while in $\mathrm{CTF}$ the loss is recorded at $60{ }^{\circ} \mathrm{C}(2.3 \%)$. A second region is observed below $600^{\circ} \mathrm{C}$, where the major weight losses are attributed to the decomposition of the carbonaceous matrix including the aromatic structures and functional groups. In samples obtained at 3, 4 and 5 min of microwave exposure this region represents an overall loss of $88-89 \%$, while in samples prepared at $2 \min (400-2$ and 500-2) the loss is $92 \%$. For sample CTF and F400 the weight loss is $94.6 \%$ and $91.3 \%$, respectively. Interesting the amount of ash was very similar for samples $400-2,500-2$ and $\mathrm{CTF}(4,4.5$ and $4.16 \%$, respectively) and these values were lower than the recorded by the samples prepared at 3, 4 and 5 min (6.68.5\%). This result and the peaks of decomposition showed for the samples 400-2 and 500-2 (Fig. 2a) at temperature of $306{ }^{\circ} \mathrm{C}$ give indication of two important facts: 1) the exposure time of 2 min of microwave are not enough for the complete depolymerization of the lignocellulosic matrix of the nut shell and significant amount of cellulose and hemicelluloses remain in char after microwave treatment. This result is in accordance with the obtained in elemental analysis where was observed the highest oxygen content for the samples 400-2 and 500-2 (20-26.1\%). Also, this result is complementary to the FT-IR spectra's and the $\mathrm{pH}_{\mathrm{pzc}}$ described previously. 2) The second important fact is the main inorganic constituent of nut shell is calcium forming hydrated calcium oxalate [22], in Fig. 3 is observed a late region of decomposition at temperatures above $600{ }^{\circ} \mathrm{C}$ attributed to the transformation of $\mathrm{CaCO}_{3} \rightarrow$ $\mathrm{CaO}+\mathrm{CO}_{2}$ [28]. The samples 400-2, 500-2 and CTF showed a mass loss of 3 and $2 \%$ related 
to this transformation while in microwave samples obtained at 3,4 and 5 min the weight loss is from 5 to $6 \%$. This could indicate that the microwave treatment increases the calcium oxalate transformation, thereby representing an advantage for wastewater treatment for the combination of ionic exchange and adsorption technologies.

In this regard, the oxygen reported in Table 2 involves the total oxygen in the sample taking in account the oxygen in the carbonaceous matrix and the inorganic matter (ash). Despite in microwave systems is not possible to measure accurately the temperature in the sample, it is possible to estimate the minimum temperature reached by the sample by analysing the inorganic compounds presented in the nut shell. In this sense, the TGA of the calcium oxalate showed in Fig. S3 (Supporting information) gives an indication of the temperature at which the calcium oxalate is converted in calcium carbonate $\left(\mathrm{CaCO}_{3}\right)$ and calcium oxide $(\mathrm{CaO})$. By comparing Fig. S2a and Fig. S3 is possible to hypothesize that samples prepared at 4-5 min were pyrolysed completely and the high oxygen percent (13-14\%) is related not only to the basic groups as pyrone, chromene, carbonyl in the carbon; is also related to the oxygen presented in the ash (7-8.5\%) as carbonate and calcium oxides.

On the other hand, the data obtained from $\mathrm{N}_{2}$ adsorption isotherms at $-196{ }^{\circ} \mathrm{C}$ were fitted to different models such as Brunauer, Emmett and Teller (BET) and Dubinin- Raduskevich, with the purpose of calculating the specific surface and the micropore volume. In general, all the isotherms are type I according with the IUPAC classification and they are typical of microporous materials (See Fig. 4). The results of the principal textural parameters are reported in Table 3, and they indicate that all the materials have a relatively low specific surface ( 2 to $320 \mathrm{~m}^{2} / \mathrm{g}$ ), compared with the commercial carbon F400 (S BET $896 \mathrm{~m}^{2} / \mathrm{g}$ ). The lower values obtained in specific surface by the microwave samples are likely to be the result 
of the lack of activating agent by which the carbonaceous materials enhance their porous structure. In this regard, the microwave heating promotes the formation of micropores by volatilization of hetero-atoms such $\mathrm{O}, \mathrm{H}$ and $\mathrm{N}$ and are eliminated as gaseous products. The adsorbent CTF showed similar specific surface ( $\mathrm{S}_{\mathrm{BET}}$ of $326 \mathrm{~m}^{2} / \mathrm{g}$ ) to the sample $500-3$ in microwave heating $\left(320 \mathrm{~m}^{2} / \mathrm{g}\right)$ and also was found to have comparative textural properties such as total pore volume $\left(\mathrm{V}_{\text {tot }}\right)\left(0.20\right.$ and $0.18 \mathrm{~cm}^{3} / \mathrm{g}$, respectively) and pore microporous volume $\left(\mathrm{V}_{\mathrm{mic}}\right)\left(0.15\right.$ and $0.16 \mathrm{~cm}^{3} / \mathrm{g}$, respectively).

The energy needed for the preparation of each carbonaceous adsorbent prepared in the microwave system was calculated, and for the sample 500-3 the energy was $6.4 \mathrm{~kJ} / \mathrm{g}$, this value was the best to complete the volatilization of less thermostable groups in nut shell and for opening blocked pores. This indicates that it is possible to obtain similar textural parameters in conventional and microwave heating, but for microwave heating the processing times are short ( $3 \mathrm{~min}$ ) compared with $268 \mathrm{~min}$ that are required in conventional heating, this could promote significant energy saving.

As shown in Table 3 it is clear that the two samples obtained with 2 min of exposure time have the lowest specific surface ( 2 and $26 \mathrm{~m}^{2} / \mathrm{g}$ for the samples 400-2 and 500-2, respectively) and with 3 min of exposure time at 400 and $500 \mathrm{~W}$ were achieved the highest specific surfaces (304 and $320 \mathrm{~m}^{2} / \mathrm{g}$, respectively). As discussed before, the processing time of $2 \mathrm{~min}$ is not enough to reach the complete volatilization of hemicelluloses and cellulose, and as result, the pores remain blocked and low specific surface is achieved. Comparing the textural properties of carbon materials at different microwave power and time, it was found at $3 \mathrm{~min}$ microwave exposure it is possible to produce adsorbents with better textural characteristics than at 4 and $5 \mathrm{~min}$. The surface area and total pore volume $\left(\mathrm{V}_{\text {tot }}\right)$ of $500-3$ and 400-3 increased by 10-fold (500-2) and 18-fold (400-2), respectively. As expected the 
textural properties increased as the microwave treatment increased from 2 to $3 \mathrm{~min}$, however, this relation was not satisfied linearly at exposure times of 4 and 5 min. Fig. S4 (supporting information) shows at higher exposure times, the specific surface starts to decrease, specifically, the sample prepared at $500 \mathrm{~W}$ and $3 \mathrm{~min}$ showed the highest specific surface area $\left(320 \mathrm{~m}^{2} / \mathrm{g}\right)$ and mesoporous volume $\left(0.5 \mathrm{~cm}^{3} / \mathrm{g}\right)$, however, when the exposure time increased to 4 and $5 \mathrm{~min}$, both specific surface area and mesoporous volume dropped to 202$224 \mathrm{~m}^{2} / \mathrm{g}$ and $0.2-0.3 \mathrm{~cm}^{3} / \mathrm{g}$, respectively. This behavior is explained by the fact that at high microwave power and high exposure time, the absorbed energy in the sample increases, overheating the material and destroying the porous structure formed at 3 minutes [22].

As was described before, the energy was obtained by numerical integration of the experimental data (See Table 3). Particularly, in Fig. S3 show $6.4 \mathrm{~kJ} / \mathrm{g}$ is the energy at which the volatilization of lignocellulosic matrix is completed, opening pores and reaching higher values of $\mathrm{S}_{\mathrm{BET}}$, and at same time, avoids the subsequent pore melting by overheating. In this regard could be expected that the samples which absorbed $6.4 \mathrm{~kJ} / \mathrm{g}$ and above might show similar specific surface area, however, in the present work was corroborated that the surface area it is not linear with the energy. For example, the sample $500-5$ absorbed $10.88 \mathrm{~kJ} / \mathrm{g}$ and showed lower specific surface area $\left(224 \mathrm{~m}^{2} / \mathrm{g}\right)$ than the sample with $6.4 \mathrm{~kJ} / \mathrm{g}$. It is evident the gap of $4.4 \mathrm{~kJ} / \mathrm{g}$ affected negatively the textural parameters. One possible explanation for this behavior could be explained because when the energy increases, the sample experienced a fast and high temperature, overheating and melting the porous structure. Comparing the textural parameter with F400, it is clear a lower porosity development due to the microwave samples prepared in the present work avoided the pre-carbonization and activation stages. Also, Table 3 shows F400 in a mesoporous activated carbon, and this feature indicates good performance in the removal of dyes with large size. 
The pore-size distribution for samples prepared in microwave heating was calculated by the Barrett-Joyner-Halenda (BJH) method and results showed a pore size distribution in average of 0.8-1.2 nm (Fig. S5, Supporting information).

\subsection{Analysis of the interaction between dyes and microporous carbonaceous adsorbents}

According the results presented in Table 1 and Fig. S5 (supporting information) all dyes used in present work are larger than the pore size of carbonaceous adsorbents prepared in microwave heating, and as a result the diffusion of dyes in the pores is not possible. Therefore, the removal of textile dyes is mainly controlled by the physico-chemical interactions between the adsorbent and the adsorbate. The adsorption depends on the properties of the dyes themselves and the surface functional groups of the carbons, due to the low specific surface area and total pore volume of the materials.

Particularly, the solution (initial) $\mathrm{pH}$ and the $\mathrm{pH}_{\mathrm{pzc}}$ of the carbons are the key parameters in the adsorption process, especially in aqueous solution. These important experimental factors determine the specific adsorbent surface charge, the ionic dissociation of dye in solution, and at the same time, the distribution of ionized species between phases. The surface chemistry of the carbons prepared in this work affects the whole dye adsorption process, whereas the solution (initial) $\mathrm{pH}$ determines both the surface charge of carbons and the degree of ionization and speciation of the functional groups of dye. The adsorption of the selected dyes on the different carbons is thus analyzed in terms of two aspects:

i) Overall charge of the dye in the aqueous solution (at a given solution $\mathrm{pH}$ )

ii) Surface charge of the carbon in the aqueous solution (at a given solution $\mathrm{pH}$ )

Results of adsorption of AO7 are shown in Fig. 5a and is relevant to mention that AO7 is an anionic molecule because, in aqueous solution, the dye is dissociated, and it has a negative 
charge. Since most of the materials have a relatively high $\mathrm{pH}_{\mathrm{pzc}}(9.6-11.8)$, they should have a positive surface charge at $\mathrm{pH} 3$ and 7 due to protonation of their basic groups. In other words, the acidic medium ( $\mathrm{pH}$ 3) is favorable for the adsorption of $\mathrm{AO} 7$; at low $\mathrm{pH}$ the protonation of the carbon surface increases, neutralizing their negative charges. As the surface is protonated, this provides more active surface of the adsorbents for the electrostatic interaction with active sites $\left(-\mathrm{SO}_{3}{ }^{-}\right)$of dye. Moreover, a clear behavior is observed for all the carbons, i.e., the adsorption capacities of $\mathrm{AO} 7$ are higher, for a given material, at $\mathrm{pH} 3$ than at $\mathrm{pH}$ 7. The increase in the adsorption capacity under acidic conditions ( $\mathrm{pH} 3$ ) can be explained as a result of a low $\mathrm{pH}$, an increase in $\mathrm{H}^{+}$ion concentration occurs, and stronger electrostatic attraction appears between the positively charged surface of the carbon and the anionic dye molecule. Similar results were reported for the adsorption of reactive black 5 [29]. In summary, for $\mathrm{AO} 7$, the $\mathrm{pH}$ of the initial solution determines the adsorption process and the maximum adsorption capacity was observed for the sample $500-5$ (20 mg/g at pH 3$)$. A possible adsorption mechanism of AO7 by the basic carbons is proposed in Fig. S6a, depicting the protonated carbon surface and its interaction with AO7, where the monosulphonated $\left(\mathrm{SO}_{3}^{-} \mathrm{Na}\right)$ dye becomes dissociated and converted to an anionic dye $\left(\mathrm{SO}_{3}^{-}\right)$ in aqueous solution. For the samples CTF and F400 the adsorption capacity was of 2 and 132 $\mathrm{mg} / \mathrm{g}$, respectively. The higher removal of this dye in F400 is as a result of their high mesopore volume and specific surface.

The influence of initial solution $\mathrm{pH}$ on the adsorption of BB9 is shown in Fig. 5b. The lower values of adsorption were obtained in acidic solutions ( $\mathrm{pH} 3)$, the decrease in BB9 removal at $\mathrm{pH} 3$ may have been due to the higher concentration of protons $\left(\mathrm{H}^{+}\right)$in adsorbent surface which competed with the cationic dye. The removal capacity of the carbons for this basic dye 
is relatively high compared to the adsorption of the other two dyes (AO7 and RB5). Results show that by decreasing the initial $\mathrm{pH}$ of the solution from 7 to 3 , the adsorbed amount decreased significantly. It should be noticed that there is a high concentration of $\mathrm{H}^{+}$ions and the cationic moiety in $\mathrm{BB} 9\left(\mathrm{~N}^{+}\right)$and the basic groups of carbons are protonated [30]. In this case, if the carbons become positively charged, repulsive forces with the cationic BB9 molecules would arise and, as a result, the adsorption capacity of the carbons should decrease at acidic $\mathrm{pH}$. The highest removal of BB9 in carbonaceous adsorbents prepared in microwave treatment was thus reached at pH 7 for sample 500-3 ( 40 mg/g), compared whit carbon CTF $(12 \mathrm{mg} / \mathrm{g})$ and F400 (101 mg/g). A potential adsorption mechanism in a carbonaceous material obtained in microwave heating is presented in Fig.S5-b.

Finally, the adsorption of RB5 was also studied at pH 3 and 7, Fig. 4c shows that this particular dye is hardly adsorbed by the carbons. Even though the sulphonate groups of the molecule can be dissociated, the molecule structure seems too big (volume $1882.6 \AA^{3}$ ) and impedes the electrostatic interaction with the surface-active sites in the adsorbent. Low removal was also reported for samples $\mathrm{CTF}$ and F400 at initial $\mathrm{pH}$ of 70.9 and $50 \mathrm{mg} / \mathrm{g}$, respectively.

The adsorption of dyes was analyzed in terms of the energy used for the preparation of the carbonaceous samples and their physicochemical properties. However, a clear trend was not found between the $\mathrm{S}_{\mathrm{BET}}$, the energy and the removal of dyes at particular $\mathrm{pH}$. This could be because the dye size is too large to enter into the micropores of the carbonaceous adsorbents. These findings are essential in terms of design parameters. Particularly in the removal of dyes, it is necessary to enlarge the micropores $(<2 \mathrm{~nm})$ formed by microwave heating, in 
order to obtain mesoporous materials (2 to $50 \mathrm{~nm}$ ) and to promote dye removal by electrostatic interaction, but also by correct mechanism of diffusion intra-particle.

Although similarities in terms of textural parameters were found by sample 500-3 and CTF, 500-3 performed better than CTF in the absorption of all 3 dyes. This result gives us indication of the surface groups (mainly basic groups) play a determining role in the electrostatic interaction between the charges surface and the dissociated dye. Comparing the two samples with similar textural features (500-3 and CTF), it was found that microwave treatment resulted in a higher content of inorganic matter (ash) $(4.16 \%$ for CTF and $6.64 \%$ for sample 500-3). This indicates that although similar textural features were observed, the microwaved sample had likely been exposed to $780^{\circ} \mathrm{C}$, the decomposition temperature of calcium oxalate, compared with $650^{\circ} \mathrm{C}$ in the conventionally pyrolyzed sample.

\subsection{Desorption studies}

The reversibility of the adsorption process on all the carbonaceous samples was studied using deionized water at the same initial $\mathrm{pH}$ of the adsorption experiments ( $\mathrm{pH} 3$ and 7). For AO7, it was found that the $\mathrm{pH}$ of the solution has little effect in the desorption process. Hence, under acidic conditions ( $\mathrm{pH} 3$ ), the desorbed percentage ranges from 17 to $20 \%$ of the initial adsorbed amount and at $\mathrm{pH} 7$ the desorbed percentage ranges from 20 to $23 \%$ (See Fig. 4a). The desorption results of BB9 dye are presented in Fig. 5b. Interestingly, the ability of carbon materials to retain BB9 is very high with desorbed percentages being much lower than those observed for AO7 (Fig. 4a) and RB5 dyes (Fig. 5c). In this case, the pH of the desorbing solution has a noticeable effect on the amount of BB9 finally desorbed, i.e. acid $\mathrm{pH}(\mathrm{pH} 3)$ renders desorption percentages of up to $9 \%$, whereas in the case of $\mathrm{pH} 7$, maximum desorption values are ca. $2.5 \%$ of the adsorbed quantities. This effect of the $\mathrm{pH}$ of the solution 
on the amount desorbed is nonetheless much more evident in the case of the RB5 dye. Differences between desorption percentages at $\mathrm{pH} 3$ and $\mathrm{pH} 7$ are 70 and $20 \%$, respectively (Fig. 5c). The significant increment in the desorption behavior of this dye compared with AO7 and BB9 could be due to the low adsorption capacity of the microporous carbons. These results indicate that both the electrostatic forces and the molecular dimensions of the dyes are crucial in order to understand the adsorption-desorption process.

\section{Conclusions}

The results obtained in the present work are indicating that it is possible to obtain microporous carbonaceous materials with similar textural parameters in conventional and microwave heating, but for microwave heating the processing times are short (3 min) compared with 268 min that are required in conventional heating, this could promote significant energy saving. Particularly, $6 \mathrm{~kJ} / \mathrm{g}$ is the energy needed to complete the volatilization of lignocellulosic matrix of pecan nut shell, opening pores and reaching higher values of $\mathrm{S}_{\mathrm{BET}}$. The microporous carbonaceous sorbents have a basic nature with no need for additional physical or chemical activation and the strong interaction of dyes with these materials was conditioned by the molecular size of the dyes, being only adsorbed on the external surface of the materials and not inside the micropores.

\section{ACKNOWLEDGEMENTS}

This work was supported by CONACyT (project AGS-2012-C02-198207) and PCTIAsturias/FEDER (EU) (GRUPIN14-117) project. Dr. Durán Jiménez acknowledges the grant (230257) received from CONACYT. 


\section{References}

[1] H. Cherifi, B. Fatiha, H. Salah, Kinetic studies on the adsorption of methylene blue onto vegetal fiber activated carbons, Appl. Surf. Sci. 282 (2013) 52- 59.

[2] P. González-García, T.A. Centeno, E. Urones-Garrote, D. Ávila-Brande, L.C. OteroDiaz, Microstructure and surface properties of lignocellulosic-based activated carbons, Appl. Surf. Sci. 265 (2013) 731- 737.

[3] A.H. Faramarzi, T. Kaghazchi, H. Ale Ebrahim, A. Afshar Ebrahimi, Experimental investigation and mathematical modeling of physical activated carbon preparation from pistachio shell, J. Anal. Appl. Pyrol. 114 (2015) 143-154.

[4] Z. Emami, S. Azizian, Preparation of activated carbon from date sphate using microwave irradiation and investigation of its capability for removal of dye pollutant from aqueous media, J. Anal. Appl. Pyrol. 108 (2014) 176-184.

[5] A.M.M. Vargas, A.L. Cazetta, C.A. Garcia, J.C.G. Moraes, E.M. Nogami, E. Lenzi W.F. Costa, V.C. Almeida, Preparation and characterization of activated carbon from a new raw lignocellulosic material: Flamboyant (Delonix regia) pods, J. Environ. Manage. 92 (2011) 178-184.

[6] K. Hjaila, R. Baccar, M. Sarrà, C.M. Gasol, P. Blánquez, Environmental impact associated with activated carbon preparation from olive-waste cake via life cycle assessment, J. Environ. Manage. 130 (2013) 242-247.

[7] F. Lian, G. Cui, Z. Liu, L. Duo, G. Zhang, B. Xing, One-step synthesis of a novel Ndoped microporous biochar derived from crop straws with high dye adsorption capacity, J. Environ. Manage. 176 (2016) 61-68. 
[8] A.A. Peláez-Cid, A.M. Herrera-González, M. Salazar-Villanueva, A. BautistaHernández, Elimination of textile dyes using activated carbons prepared from vegetable residues and their characterization. J. Environ. Manage. 181(2016) 269278.

[9] V. Da Silva-Lacerda, J.B. López-Sotelo, A. Correa-Guimaraes, Hernández-Navarro, M. Sánchez-Báscones, L.M. Navas-Gracia, P. Martín-Ramos, J. Martín-Gil, Rhodamine B removal with activated carbons obtained from lignocellulosic waste, J. Environ. Manage. 155 (2015), 67-76.

[10] W. Li, X. Wang, J. Peng, Effects of microwave heating on porous structure of regenerated powdered activated carbon used in xylose, Environmental Technol. 35 (2014) 532-540.

[11] J.A. Menéndez, A. Arenillas, B. Fidalgo, Y. Fernández, L. Zubizarreta, E.G. Calvo, J.M. Bermúdez, Microwave heating processes involving carbon materials, Fuel Process. Technol. 91 (2010) 1-8.

[12] N. Ferrera-Lorenzo, E. Fuente, I. Suárez-Ruiz, B. Ruiz, KOH activated carbon from conventional and microwave heating system of a macroalgae waste from the AgarAgar industry, Fuel Process. Technol. 121 (2014) 25-31.

[13] D. Xin-hui, C. Srinivasakannan, P. Jin-hui, Z. Li-bo, Z. Zheng-yong, Preparation of activated carbon from Jatropha hull with microwave heating: Optimization using response surface methodology, Fuel Process. Technol. 92 (2011) 394-400.

[14] U. Khalil, O. Muraza, Microwave-assisted hydrothermal synthesis of mordenite zeolite: Optimization of synthesis parameters, Micropor. Mesopor. Mat. 232 (2016) 211-217. 
[15] L. Bai, G. Nan, Y. Wang, D. Hu, G. Zeng, Y. Zhang, M. Li, W. Wei, Y. Sun, Ultrafast microwave synthesis of all-silica DDR zeolites, Micropor. Mesopor. Mat. 228 (2016) 54-58.

[16] H. Deng, G. Zhang, X. Xu, G. Tao, J. Dai, Optimization of preparation of activated carbon from cotton stalk by microwave assisted phosphoric acid-chemical activation, J. Hazard. Mater. 182 (2010) 217-224.

[17] O. Pezoti, A.L. Cazetta, R.C. Gomes, É.O. Barizão, I.P.A.F. Souza, A.C. Martins, T. Asefa, V.C. Almeida, Synthesis of $\mathrm{ZnCl}_{2}$ activated carbon from macadamia nut endocarp (Macadamia integrifolia) by microwave-assisted pyrolysis: Optimization using RSM and methylene blue adsorption. J. Anal. Appl. Pyrol. 105 (2014) 166-176.

[18] Y. Wang, X. Wang, X. Wang, M. Lui, L. Yang, Z. Wu, S. Xia, J. Zhao, Adsorption of $\mathrm{Pb}$ (II) in aqueous solutions by bamboo charcoal modified with $\mathrm{KMnO}_{4}$ via microwave irradiation, Colloid Surface A. 414 (2012) 1-8.

[19] K.Y. Foo, B.H. Hameed, Adsorption characteristics of industrial solid waste derived activated carbon prepared by microwave heating for methylene blue, Fuel Process. Technol. 99 (2012) 103-109.

[20] N.M. Mubarak, A. Kundu, J.N. Sahu, E.C. Abdullah, Synthesis of palm oil empty fruit bunch magnetic pyrolytic char impregnating with $\mathrm{FeCl}_{3}$ by microwave heating technique, Biomass Bioenerg. 61 (2013) 265-275.

[21] K.Y. Foo, B.H. Hameed, Mesoporous activated carbon from wood sawdust by $\mathrm{K}_{2} \mathrm{CO}_{3}$ activation using microwave heating. Bioresource Technol. 111 (2012) 425-432.

[22] G. Durán-Jiménez, T. Monti, J.J. Titman, V. Hernandez-Montoya, S.W. Kingman, E.R Binner, New insights into microwave pyrolysis of biomass: Preparation 
ofcarbon-based products from pecan nutshells and their application in wastewater treatment. J. Anal. Appl. Pyrol. 124 (2017) 113-121.

[23] V. Hernandez-Montoya, D.I. Mendoza-Castillo, A. Bonilla-Petriciolet, M.A. MontesMoran, M.A. Pérez-Cruz, Role of the pericarp of Carya illinoinensis as biosorbent and as precursor of activated carbon for the removal of lead and acid blue 25 in aqueous solutions. J. Anal. Appl. Pyrol. 92 (2011) 143-151.

[24] G. Durán-Jiménez, V. Hernández-Montoya, M.A. Montes-Morán, M. Teutli-león, New oxygenated carbonaceous adsorbents prepared by combined radiant/microwave heating for the removal of $\mathrm{Pb}^{2+}$ in aqueous solution, J. Anal. Appl. Pyrol. 113 (2015) 599-605.

[25] J. Liang, T. Qu, X. Kun, Y. Zhang, S. Chen, Y-C Cao, M. Xie, X. Guo, Microwave assisted synthesis of camellia oleifera shell-derived porous carbon with rich oxygen functionalities and superior supercapacitor performance, Appl. Surf. Sci. 436 (2018) 934-940.

[26] M.M. Dávila-Jiménez, M.P. Elizalde-González, V. Hernández-Montoya, Performance of mango seed adsorbents in the adsorption of anthraquinone and azo acid dyes in single and binary aqueous solutions. Bioresource Technol. 100 (2009) 6199-6206.

[27] Y. Guo, D.A. Rockstraw, Physical and chemical properties of carbons synthesized from xylan, cellulose, and Kraft lignin by $\mathrm{H}_{3} \mathrm{PO}_{4}$ activation, Carbon 44 (2006) 14641475. 
[28] P.P.C. Faria, J.J.M. Orfao, M.F. Pereira, Adsorption of anionic and cationic dyes on activated carbons with different surface chemistries, Water. Res. 38 (2004) $2043-$ 2052.

[29] F. Güzel, S. Hasan, A.S. Gülbahar, K. Filiz, New low-cost nanoporous carbonaceous adsorbent developed from carob (Ceratonia siliqua) processing industry waste for the adsorption of anionic textile dye: Characterization, equilibrium and kinetic modeling. J. Mol. Liq. 206 (2015) 244-255.

[30] A.A. Hoffmann, S.L.P. Dias, , Rodríguez, J.R, Pavan, F.A., Benvenutti, E.V., Lima, E.C., Braz, 2008. Methylene blue immobilized on cellulose acetate with titanium dioxide: an application as sensor for ascorbic acid. J. Chem. Soc.19, 943-949. 
Graphical Abstract

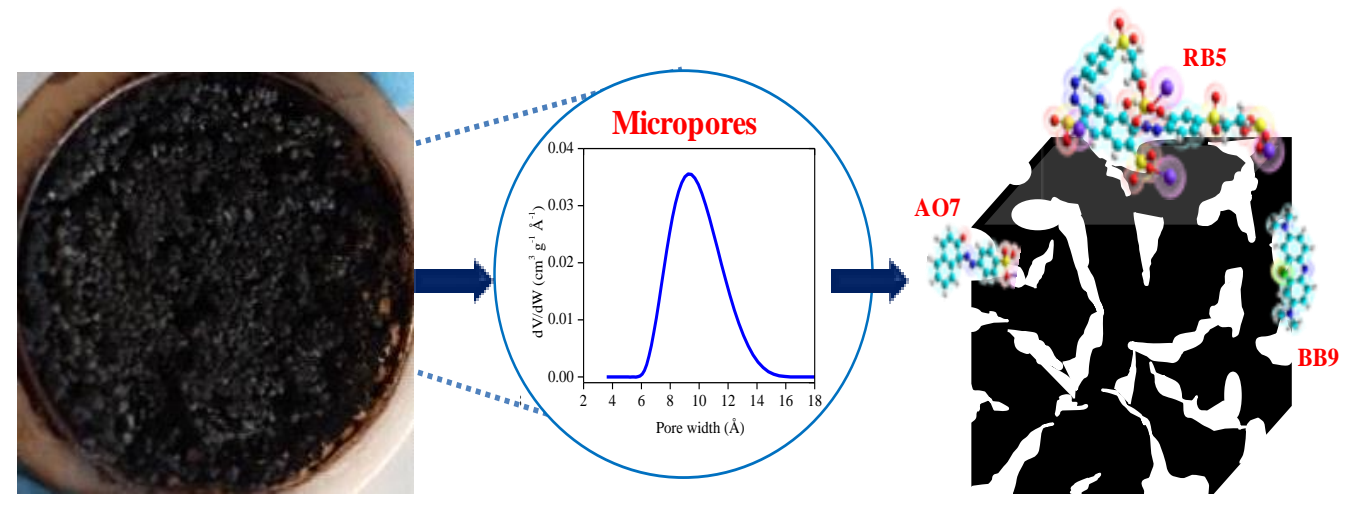




\section{Captions}

Fig. 1 Schematic representation of the microwave system used in the pyrolysis of pecan nut shells.

Fig. 2 FT-IR spectra of the carbons prepared at 400 and $500 \mathrm{~W}$ of microwave radiation.

Fig. 3 TG (continuous line) and DTG (dotted line) curves in air atmosphere of the carbons prepared at 2, 3, 4 and 5 min of microwave exposure time (a,b,c,d), conventional carbon (CTF) (e) and F400 (f).

Fig. 4 Nitrogen adsorption isotherms at $-196{ }^{\circ} \mathrm{C}$ of carbons prepared at 400 and $500 \mathrm{~W}$ of microwave radiation.

Fig. 5 Adsorption/desorption of AO7 (a), BB9 (b) and RB5 (c) on carbons prepared at 400 and $500 \mathrm{~W}$ of microwave radiation. Experimental conditions: $\mathrm{pH} 3$ and 7, mass/volume ratio: $2 \mathrm{~g} / \mathrm{L}$, temperature: $30^{\circ} \mathrm{C}$, equilibrium time: $72 \mathrm{~h}$. 
Fig. 1

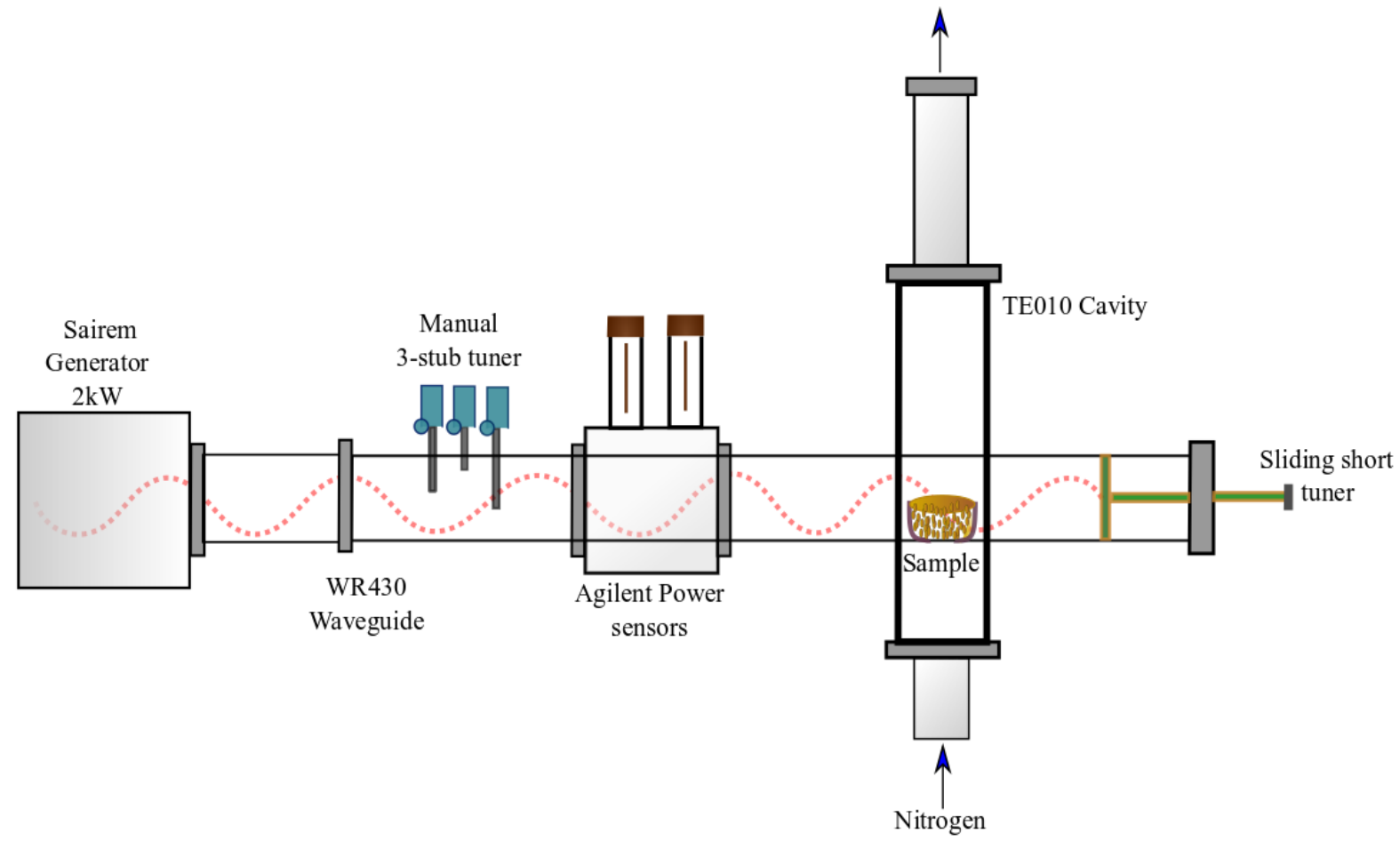


Fig. 2
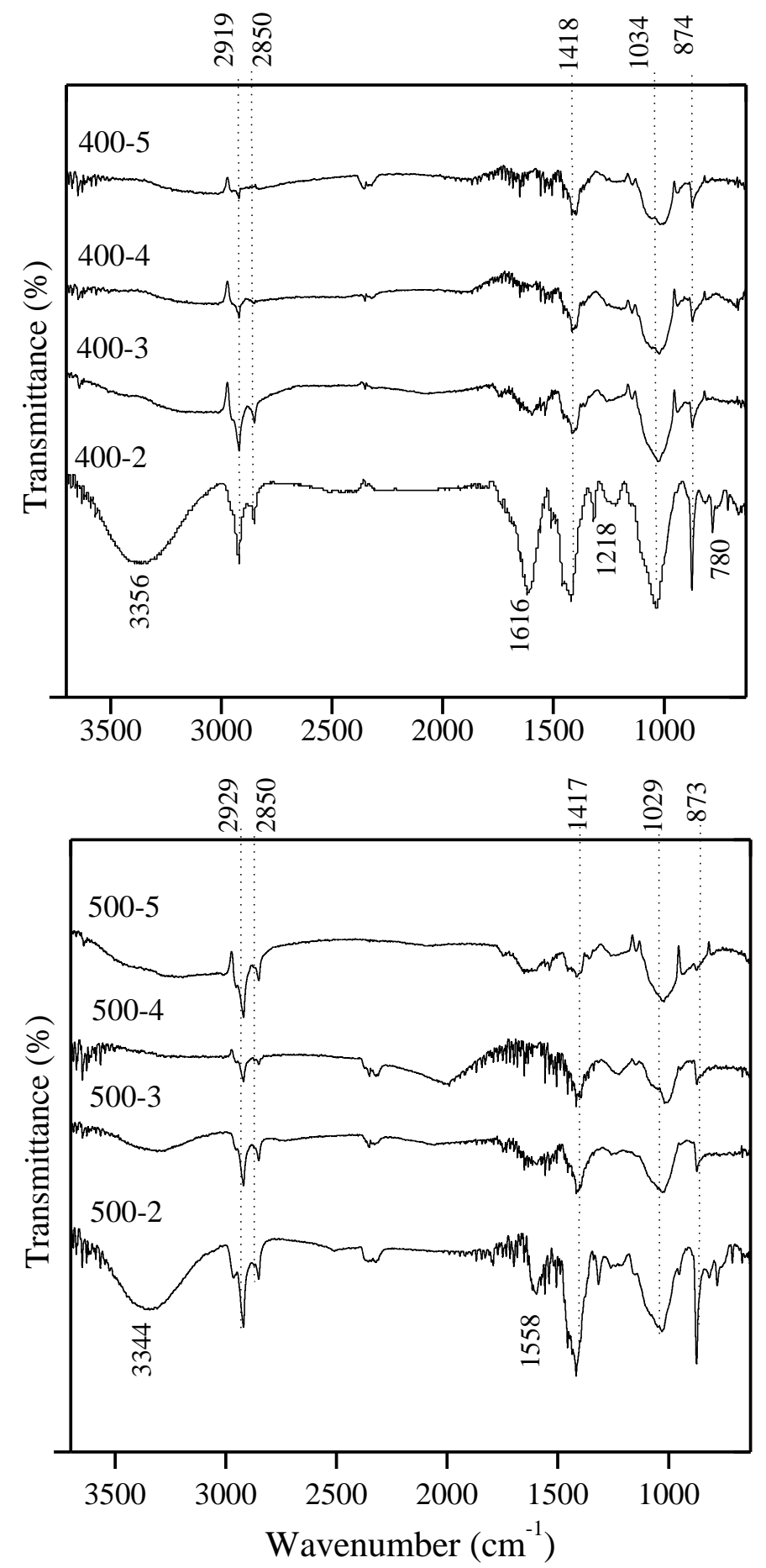
Fig. 3
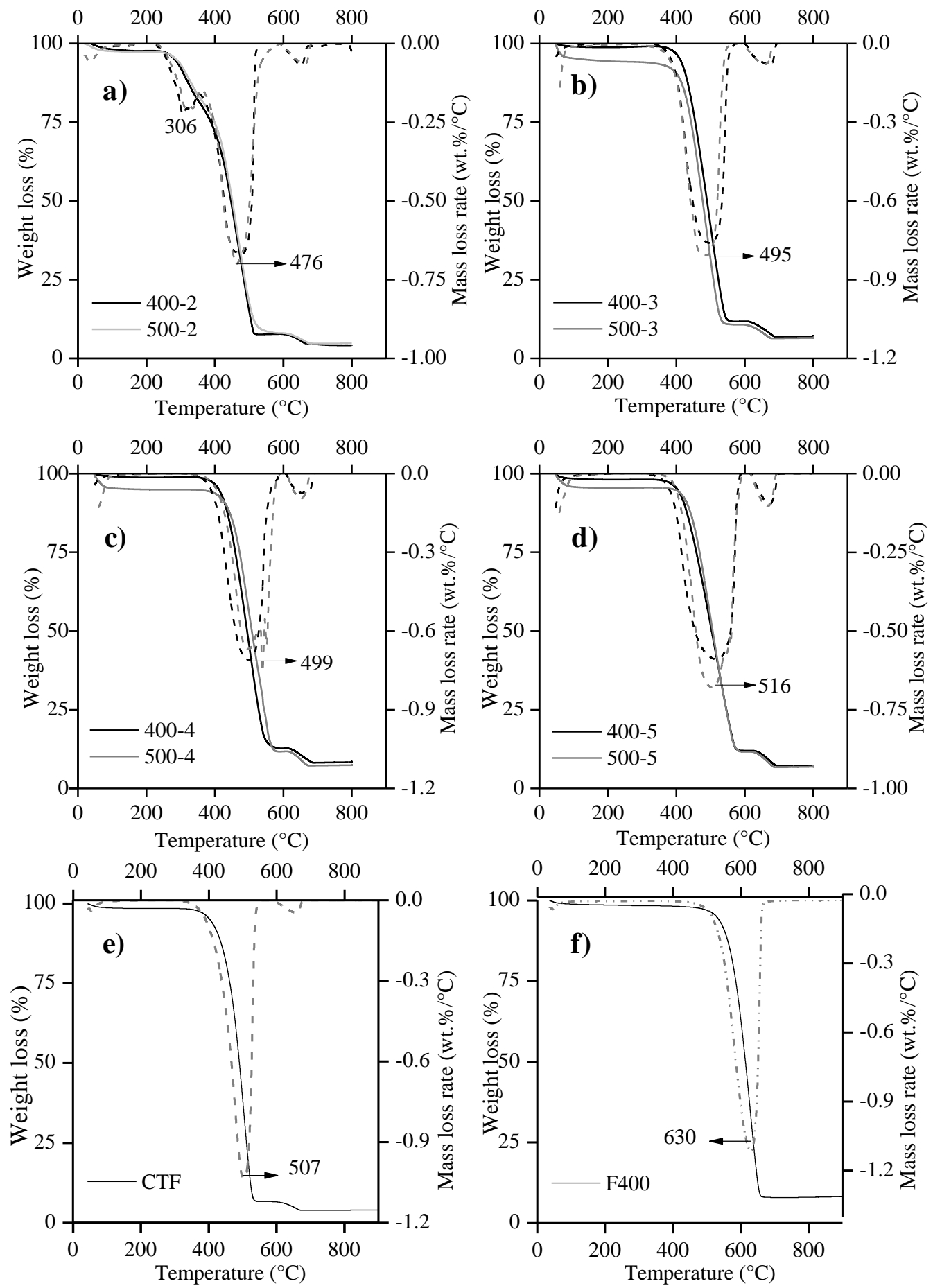
Fig. 4

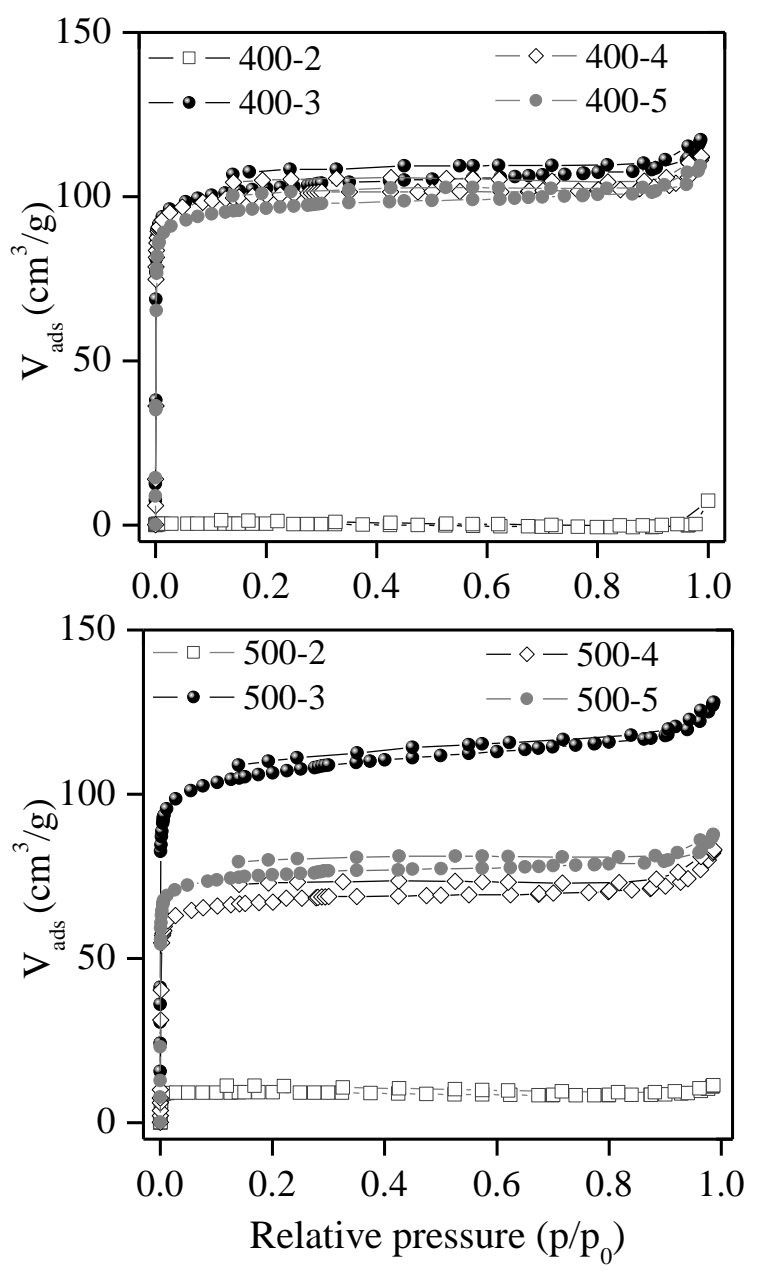


Fig. 5 
a)

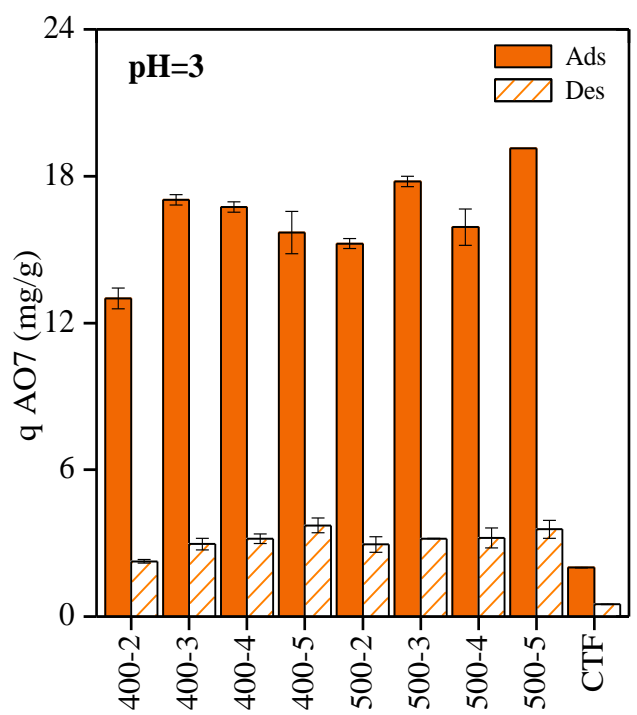

b)

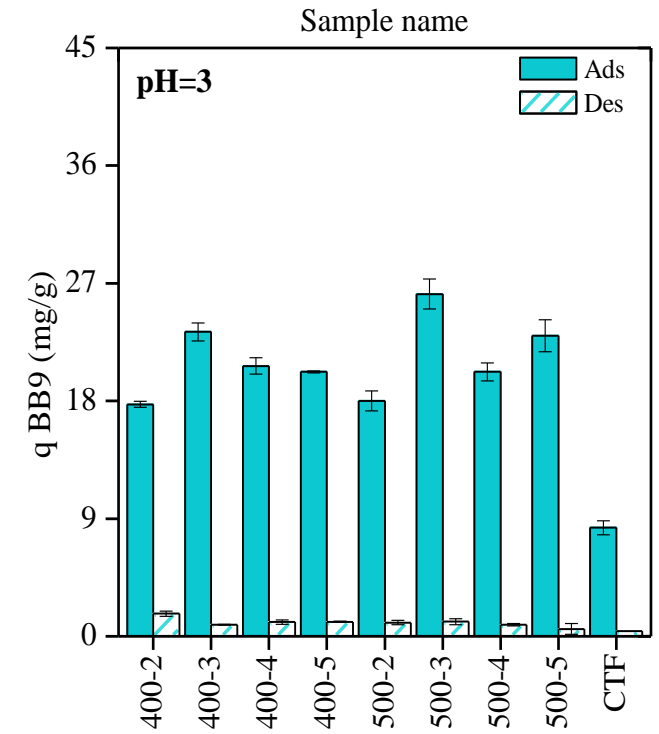

c)

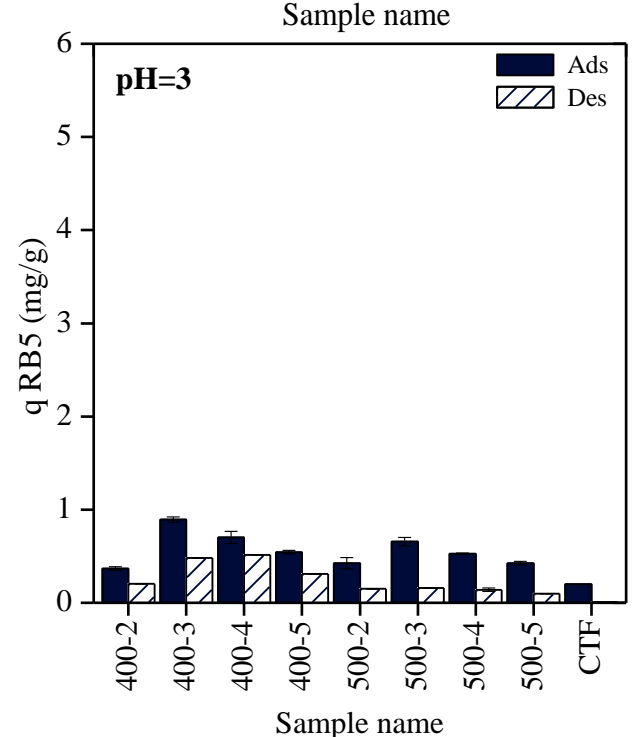

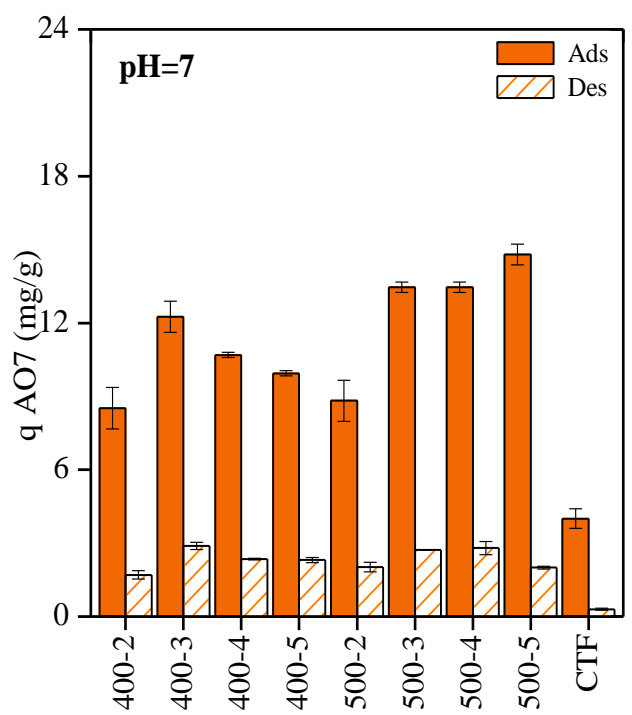
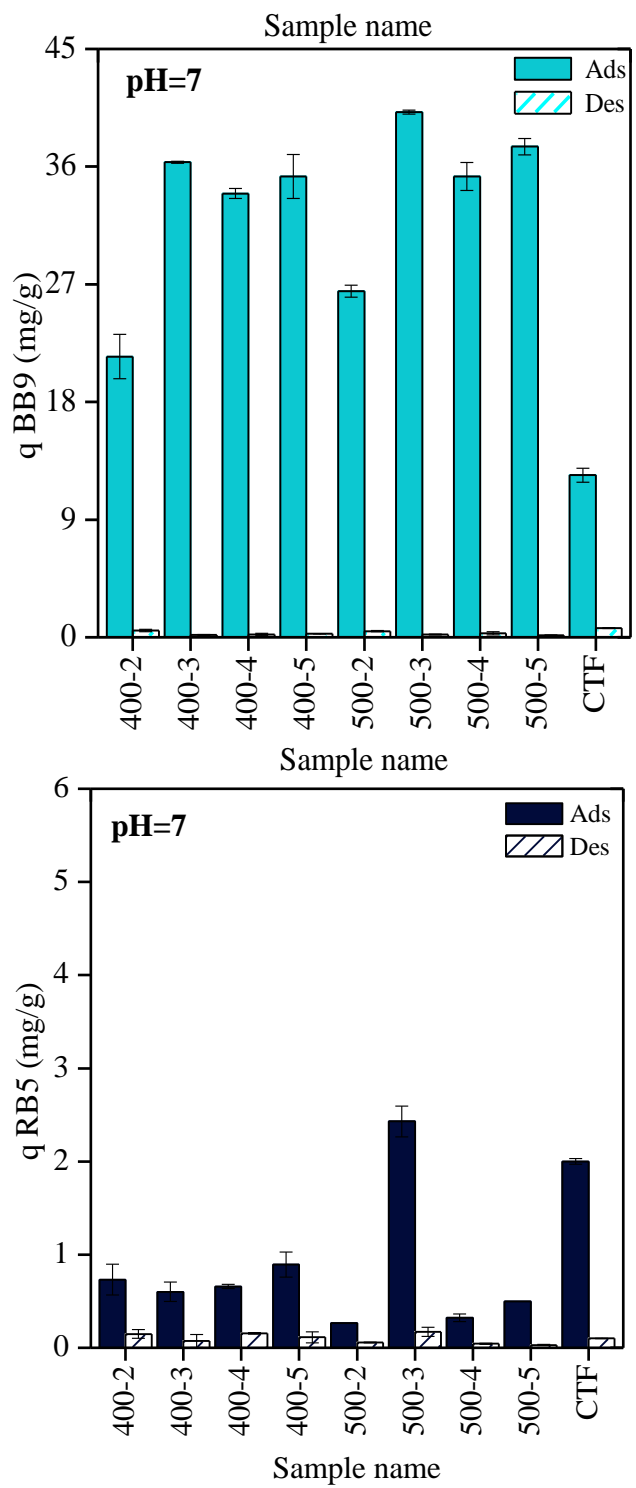
Table 1. General characteristics of the studied dyes and dimensions calculated by optimized geometries using HyperChem 8.0 software

\begin{tabular}{|c|c|c|c|c|c|c|}
\hline $\begin{array}{l}\text { Generic } \\
\text { name (code) }\end{array}$ & $\begin{array}{c}\text { Mass }(\mathrm{amu}) / \\
\text { Condensed } \\
\text { structure }\end{array}$ & Structure & $\begin{array}{c}{ }^{\mathrm{a}} \lambda \\
\mathrm{ma} \\
\mathrm{x} \\
(\mathrm{n} \\
\mathrm{m} \\
)\end{array}$ & $\begin{array}{c}\text { Are } \\
\mathrm{a} \\
\left(\AA^{2}\right)\end{array}$ & $\begin{array}{l}\text { Volu } \\
\text { me } \\
\left(\AA^{3}\right)\end{array}$ & $\begin{array}{l}\text { Lo } \\
\text { g P }\end{array}$ \\
\hline Acid Orange & 350.3 & & 48 & 488. & 894. & 1.7 \\
\hline $\begin{array}{l}7 \\
(\mathrm{AO} 7)\end{array}$ & $\begin{array}{l}\mathrm{C}_{16} \mathrm{H}_{11} \mathrm{~N}_{2} \mathrm{Na} \\
\mathrm{O}_{4} \mathrm{~S}\end{array}$ & & 4 & 5 & 4 & 7 \\
\hline Reactive & 991.8 & & 59 & 996. & 1882 & - \\
\hline $\begin{array}{l}\text { Black } 5 \\
\text { (RB5) }\end{array}$ & $\begin{array}{l}\mathrm{C}_{26} \mathrm{H}_{21} \mathrm{~N}_{5} \mathrm{Na}_{4} \\
\mathrm{O}_{19} \mathrm{~S}_{6}\end{array}$ & & 7 & 7 & .6 & $\begin{array}{l}6.1 \\
0\end{array}$ \\
\hline Basic Blue 9 & 319.8 & & 66 & 515. & 902. & - \\
\hline (BB9) & $\mathrm{C}_{16} \mathrm{H}_{18} \mathrm{ClN}_{3} \mathrm{~S}$ & & 4 & 4 & 3 & 0.4 \\
\hline
\end{tabular}

${ }^{\mathrm{a}} \lambda_{\max }$ : maximum wavelength of absorbance 
Table 2. Elemental composition and ash content of carbons prepared by microwave technology

\begin{tabular}{|c|c|c|c|c|c|c|c|c|}
\hline \multirow[b]{2}{*}{ Sample name } & \multicolumn{2}{|c|}{$\begin{array}{l}\text { Preparation } \\
\text { conditions }\end{array}$} & \multicolumn{5}{|c|}{ Elemental composition } & \multirow[t]{2}{*}{$\begin{array}{c}{ }^{\mathrm{b}} \text { Temperature, } \\
{ }^{\circ} \mathrm{C}\end{array}$} \\
\hline & $\begin{array}{l}\text { Input } \\
\text { power } \\
\text { (W) }\end{array}$ & $\begin{array}{l}\text { Holding } \\
\text { time (min) }\end{array}$ & \multicolumn{5}{|c|}{$\mathrm{C}, \% \quad \mathrm{~N}, \% \quad \mathrm{H}, \%$} & \\
\hline $400-2$ & 400 & 2 & 69.93 & 0.15 & 3.80 & 26.11 & 4.00 & 327 \\
\hline $400-3$ & 400 & 3 & 82.01 & 0.06 & 1.28 & 16.65 & 7.08 & 334 \\
\hline $400-4$ & 400 & 4 & 84.98 & 0.08 & 1.11 & 13.82 & 8.51 & 341 \\
\hline $400-5$ & 400 & 5 & 85.77 & 0.14 & 1.04 & 13.05 & 7.38 & 355 \\
\hline $500-2$ & 500 & 2 & 76.61 & 0.14 & 3.18 & 20.07 & 4.79 & 328 \\
\hline $500-3$ & 500 & 3 & 83.82 & 0.15 & 0.76 & 15.28 & 6.64 & 339 \\
\hline $500-4$ & 500 & 4 & 84.57 & 0.06 & 0.83 & 14.54 & 7.53 & 348 \\
\hline $500-5$ & 500 & 5 & 85.64 & 0.15 & 0.74 & 13.47 & 7.07 & 363 \\
\hline
\end{tabular}

${ }^{\mathrm{a} C a l c u l a t e d ~ b y ~ d i f f e r e n c e ~}$

${ }^{\mathrm{b}}$ Surface temperature of the samples after each run taken with an infrared temperature gun 
Table 3. Textural parameters of carbons prepared by microwave technology obtained from nitrogen adsorption isotherms at $-196^{\circ} \mathrm{C}$, point of zero charge (pHpzc) and energy needed for the preparation of each carbonaceous adsorbent prepared in the microwave system

\begin{tabular}{|c|c|c|c|c|c|c|c|c|}
\hline \multirow{2}{*}{$\begin{array}{l}\text { Sampl } \\
\text { e }\end{array}$} & $\begin{array}{l}\text { Prep } \\
\text { con }\end{array}$ & $\begin{array}{l}\text { Iration } \\
\text { itions }\end{array}$ & & \multicolumn{4}{|c|}{ Textural parameters } & \multirow{2}{*}{$\begin{array}{c}\mathrm{pH}_{\mathrm{pz}} \\
\mathrm{c}\end{array}$} \\
\hline & $\begin{array}{l}\text { Input } \\
\text { powe } \\
\text { r (W) }\end{array}$ & $\begin{array}{l}\text { Holdin } \\
\text { g time } \\
\text { (min) }\end{array}$ & $\begin{array}{c}\text { Energ } \\
y \\
(\mathrm{~kJ} / \mathrm{g})\end{array}$ & $\begin{array}{c}\mathrm{S}_{\mathrm{BET}}, \mathrm{m}^{2} / \\
\mathrm{g}\end{array}$ & $\begin{array}{c}\mathrm{V}_{\text {tot }} \\
\mathrm{cm}^{3} / \mathrm{g}\end{array}$ & $\begin{array}{l}\mathrm{V}_{\text {mic }} \\
\mathrm{cm}^{3} / \mathrm{g}\end{array}$ & $\begin{array}{l}V_{\text {mes }} \\
\mathrm{cm}^{3} / \mathrm{g}\end{array}$ & \\
\hline $400-2$ & 400 & 2 & 3.51 & 2 & 0.01 & 0.00 & 0.01 & 6.4 \\
\hline $400-3$ & 400 & 3 & 5.42 & 305 & 0.18 & 0.15 & 0.03 & 11.6 \\
\hline $400-4$ & 400 & 4 & 7.38 & 297 & 0.17 & 0.14 & 0.03 & 11.6 \\
\hline $400-5$ & 400 & 5 & 9.19 & 287 & 0.17 & 0.14 & 0.02 & 11.7 \\
\hline $500-2$ & 500 & 2 & 3.94 & 26 & 0.02 & 0.02 & 0.00 & 9.6 \\
\hline $500-3$ & 500 & 3 & 6.41 & 320 & 0.20 & 0.15 & 0.05 & 11.5 \\
\hline $500-4$ & 500 & 4 & 8.61 & 202 & 0.13 & 0.10 & 0.02 & 11.7 \\
\hline $500-5$ & 500 & 5 & 10.88 & 224 & 0.14 & 0.11 & 0.03 & 11.8 \\
\hline
\end{tabular}




\section{Supplementary Information}
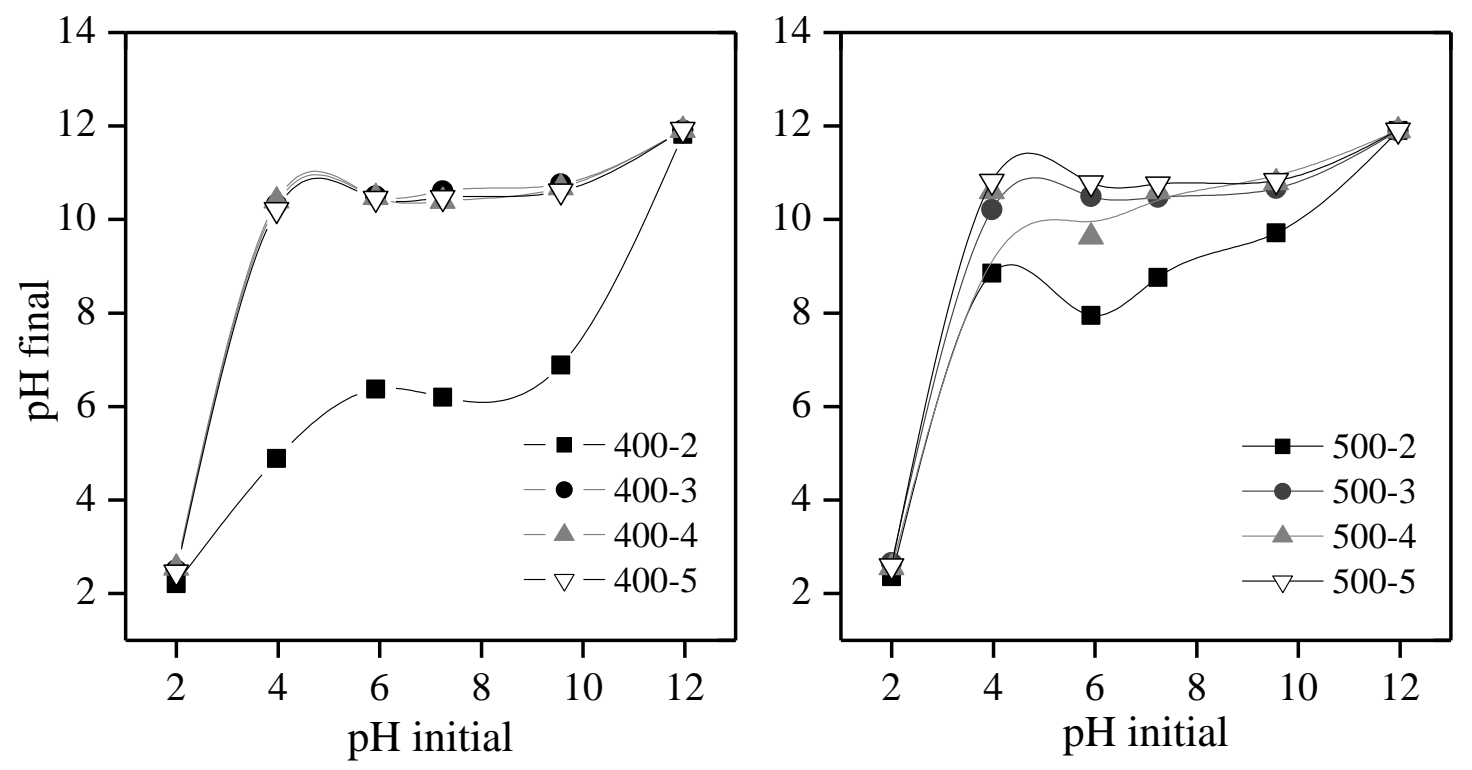

Fig. S1 Point of zero charge ( $\mathrm{pH}_{\mathrm{PZC}}$ ) of the carbons prepared at 400 and $500 \mathrm{~W}$ using microwave technology 

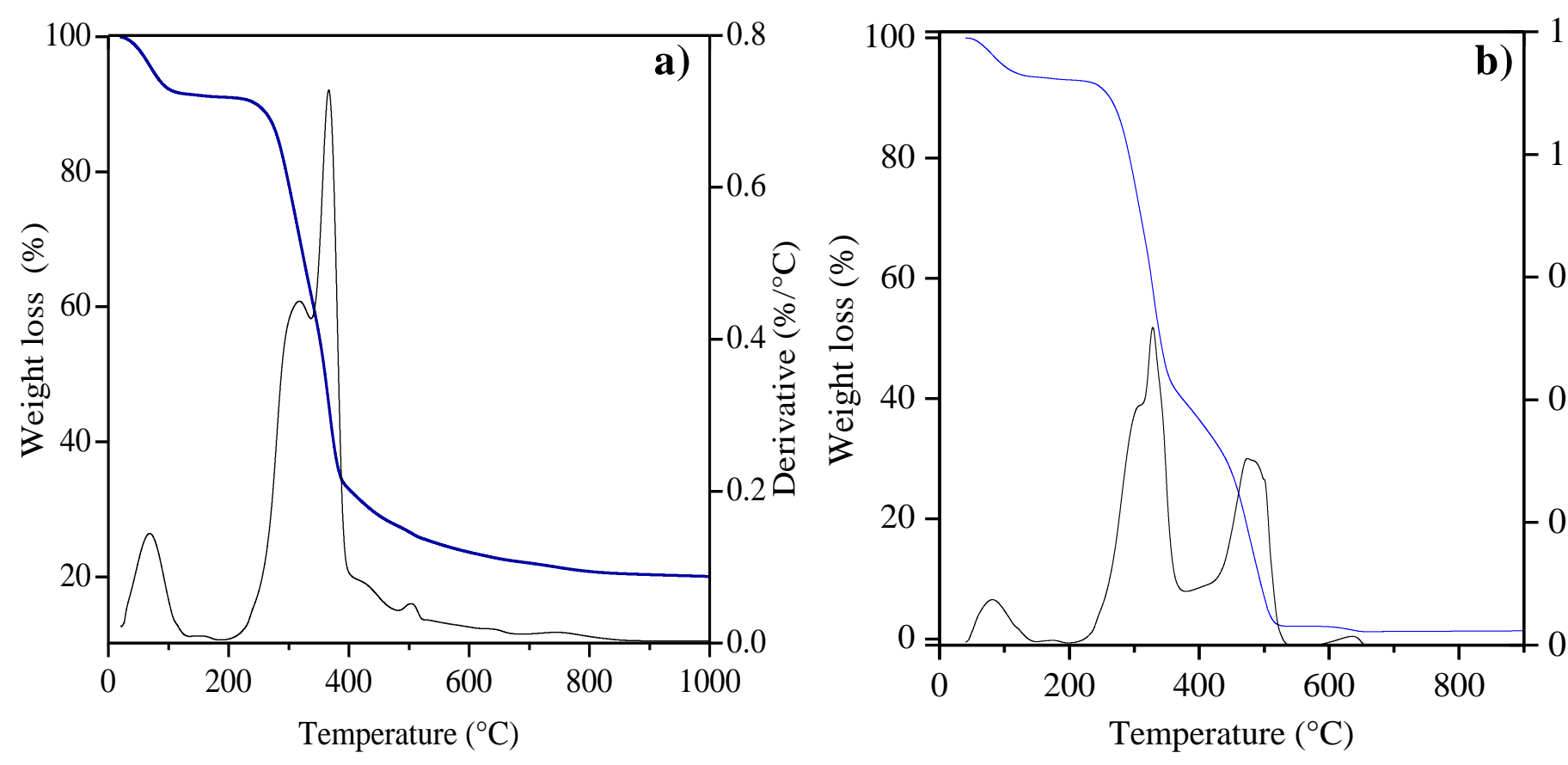

Fig. S2 TG (blue line) and DTG (black line) curves in nitrogen (a) and air (b) atmosphere of pecan nut shell 


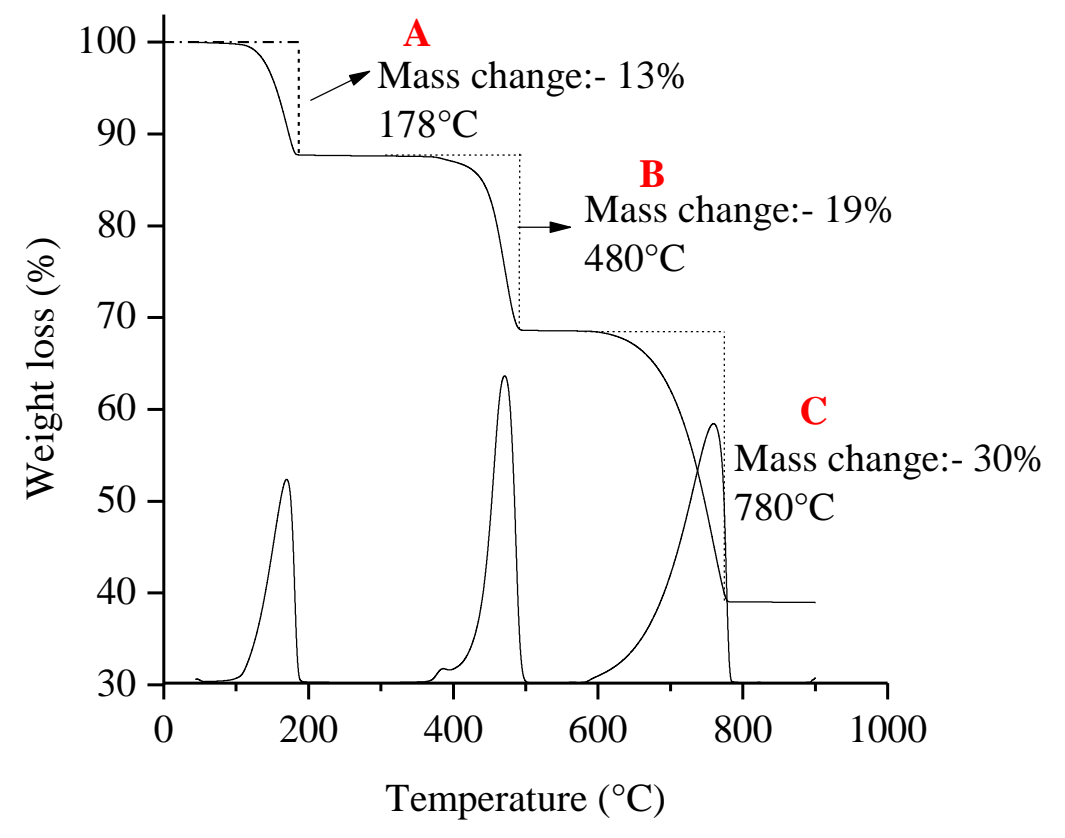

Fig. S3 TG and DTG curves in nitrogen atmosphere of calcium oxalate. Step A:

$\mathrm{CaC}_{2} \mathrm{O}_{4} \cdot \mathrm{H}_{2} \mathrm{O} \rightarrow \mathrm{CaC}_{2} \mathrm{O}_{4}+\mathrm{H}_{2} \mathrm{O}$. Step B: $\mathrm{CaC}_{2} \mathrm{O}_{4} \rightarrow \mathrm{CaCO}_{3}+$ CO. Step C: $\mathrm{CaCO}_{3} \rightarrow \mathrm{CaO}$ $+\mathrm{CO}_{2}$ 

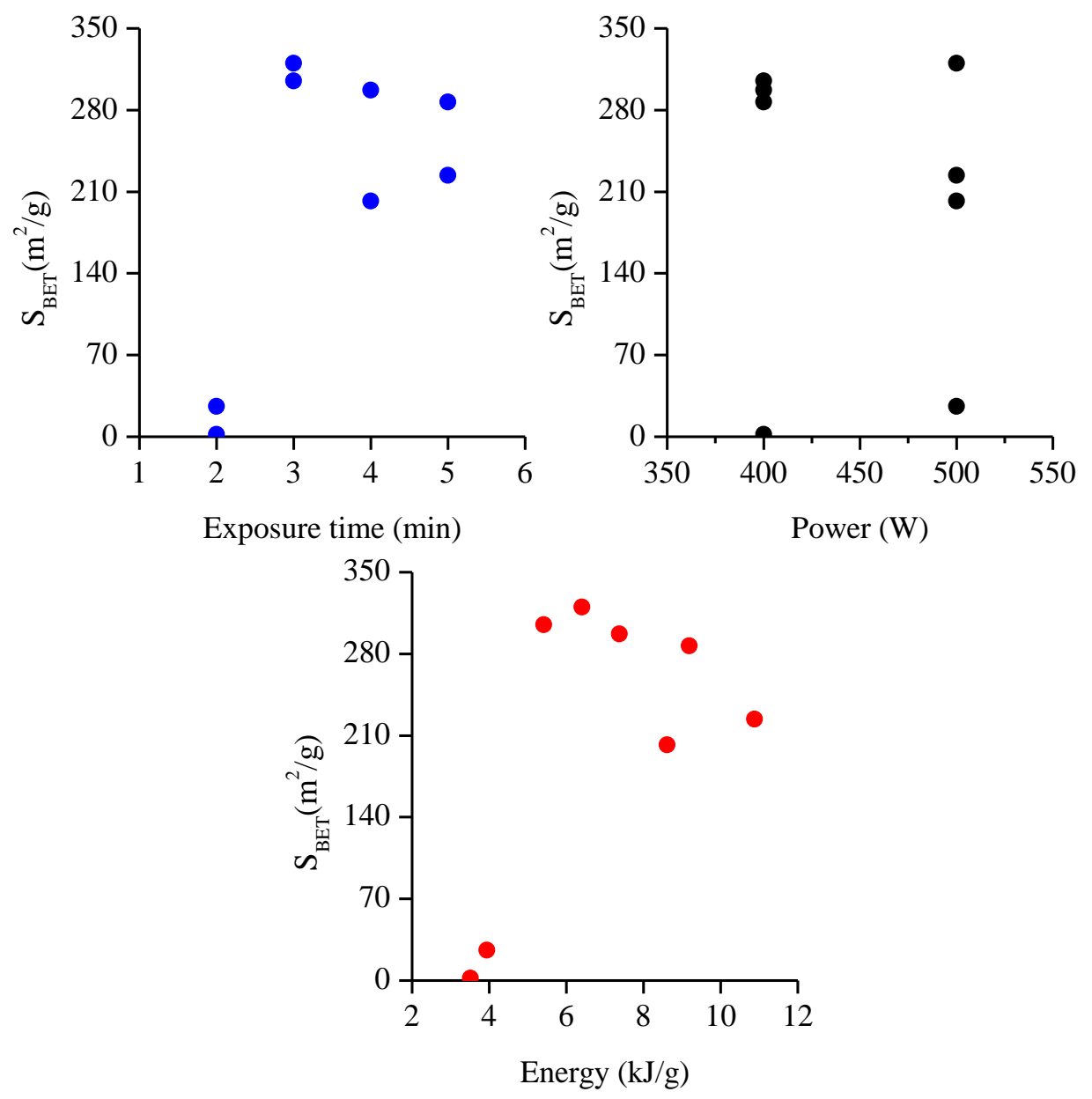

Fig. S4 Specific surface of carbonaceous adsorbents as function of microwave exposure time, microwave power and energy. 

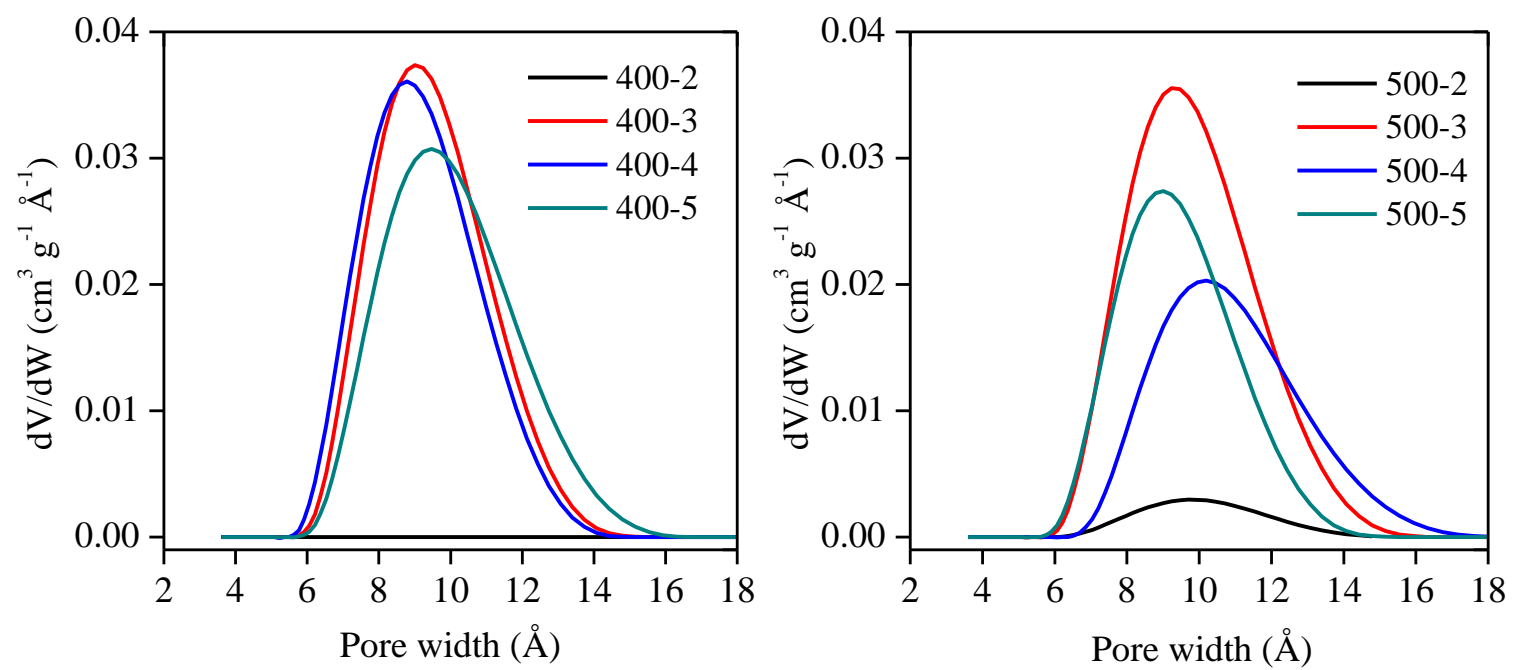

Fig. S5 Pore size distribution of the carbons prepared at 400 and $500 \mathrm{~W}$ using microwave technology 


$$
\text { " }
$$

